\title{
Chorionic gonadotrophin in the mouse from implantation to term
}

\author{
L. Wide and Mariann Wide* \\ Department of Clinical Chemistry, University Hospital, S-750 14 Uppsala, and \\ *Institute of Zoology and *Department of Anatomy, University of Uppsala, Sweden
}

\begin{abstract}
Summary. Chorionic gonadotrophin (CG) in implantation sites from Days 5 to 12 and placentae from Days 13 to 19 of pregnancy in the mouse was determined by utilizing a cross-reaction with human $C G$ in a radioimmunoassay. Significant amounts of $\mathrm{CG}$ could be detected throughout the period of gestation investigated. The amount of CG per implantation site increased steadily from Day 5 to a peak on Day 11. In the second part of pregnancy a second peak was observed with the highest amount of CG per placenta found on Day 16. No gonadotrophic activity could be detected in blastocysts flushed from the uteri on Day 5 of pregnancy or in uteri of non-pregnant mice.
\end{abstract}

\section{Introduction}

Evidence has been presented that a factor similar to human chorionic gonadotrophin (CG) with alpha- and beta-subunits is present in mouse placentae of Day 15 of pregnancy (Wide \& Hobson, 1978). It is not known whether this mouse CG is detectable before and after Day 15 of pregnancy. In the present study we have attempted to measure mouse CG in the conceptus or placenta from the attachment stage of implantation (Day 5 of pregnancy) throughout pregnancy. The possible presence of CG in mouse blastocysts flushed from the uterine horns on Day 5 was also investigated.

\section{Materials and Methods}

Virgin albino mice of the NMRI strain, about 8 weeks old and weighing $25-27 \mathrm{~g}$, were caged with males overnight and the day on which a vaginal plug was found was taken as Day 1 of pregnancy. The animals were killed by cervical dislocation, and the uterine horns were excised. On Day 5 of pregnancy implantation sites, localized by i.v. injection of $0.1 \mathrm{ml} 1 \%$ Pontamine Sky Blue solution (Psychoyos, 1971), were collected by cutting the uteri transversely. From Days 6 to 12 of pregnancy the implantation sites were collected by cutting uteri on either side of each decidual swelling. From Days 13 to 19 chorioallantoic placentae were collected. The number of conceptuses/animal ranged from 7 to 13. The numbers of pooled implantation sites or placentae for each day of pregnancy studied are given in Table 1. All implantation sites and placentae from the same day of pregnancy were pooled, kept deep-frozen, and weighed before being homogenized in ice-cold acetone $(5 \mathrm{ml} / \mathrm{g})$ plus ice-cold ether $(1 \mathrm{ml} / \mathrm{g})$ as described by Hobson (1972). The tissue extracts were kept at $+4^{\circ} \mathrm{C}$ overnight and centrifuged. The tissue residue was washed in acetone plus ether, air dried at room temperature, and kept at $-20^{\circ} \mathrm{C}$ until analysed. The acetone-ether precipitates were then dissolved in saline $(9 \mathrm{~g} \mathrm{NaCl} / \mathrm{l})$, left overnight at $+4^{\circ} \mathrm{C}$ and centrifuged. Uteri taken from 10 virgin mice, without regard to the day of their oestrous cycle, were used as controls. 
On Day 5 of pregnancy 24 mice were used for flushing of blastocysts. The uterine horns were excised and blastocysts were flushed with a $0.15 \mathrm{M}$-phosphate-buffered saline (PBS) solution, $\mathrm{pH} 7 \cdot 2$, containing $1 \%$ bovine serum albumin (BSA). A total of 98 blastocysts was collected in $0.5 \mathrm{ml}$ PBS-BSA solution and kept deep-frozen before treatment with acetone (5 $\mathrm{ml} / \mathrm{ml}$ ) and ether $(1 \mathrm{ml} / \mathrm{ml})$ as described above. The precipitate from the blastocyst preparation. was dissolved in $1.0 \mathrm{ml}$ saline.

The saline extracts of the acetone-ether precipitates were assayed by a solid-phase radioimmunoassay (Wide, 1969). The assay method for mouse CG activity was based upon a previously shown immunological cross-reaction between human $\mathrm{CG}$ (hCG) and mouse CG (Wide \& Hobson, 1978). The reagents were ${ }^{125} \mathrm{I}$-labelled hCG and a rabbit hCG-antiserum coupled to $\mathrm{CNBr}$-activated Sephadex. The samples were incubated with the solid phase-coupled antibodies for 6 days at room temperature and subsequently for 1 day with addition of labelled antigen. The unknown samples were tested in 5 or 6 concentrations with a log dose interval of 0.301 and 2 or 4 replicates of each dose. Mean values and $95 \%$ fiducial limits of the mean were calculated from within-assay variation of 9-15 estimations of each extract.

The extract of the Day 6 implantation sites was used as a provisional calibration standard in the CG assay as there is no mouse CG standard available. The effect of mouse CG in the pool of 147 Day-6 implantation sites was assigned the value of 147 arbitrary units $\left(U_{\text {arb }}\right)$. There was not a complete parallelism between this mouse CG standard and the 2nd International Standard for hCG and this precluded the latter from being used as a calibration standard in the assay. The sensitivity of the assay was $0.1 \mathrm{U}_{\text {arb }}$ mouse $\mathrm{CG}$ or equivalent to $0.02 \mathrm{ng} \mathrm{hCG}$.

A control of the specificity of the method for assaying mouse CG in implantation sites of early pregnancy was made by a chromatographic study on a pooled extract of implantation sites from Days $6(n=35)$ and $7(n=23)$ of pregnancy. Molecular sieve chromatography on Sephadex G-200 (Pharmacia AB, Uppsala, Sweden) of the extract, dialysed against the elution buffer, was performed as previously described for an extract of mouse placentae of Day 15 of pregnancy (Wide \& Hobson, 1978). The eluted material was tested for cross-reactivity in solidphase radioimmunoassay systems for hCG, the hCG beta-subunit, and the hCG alpha-subunit. The activities expressed in relation to those of purified preparations of hCG and its subunits were plotted in relation to the degree of retardation in the column, expressed in $K_{\mathrm{av}}$ values, as shown in Text-fig. 1. The elution patterns from the 3 assays were very similar to those of the extract of mouse placentae from Day 15 of pregnancy. With the assay using ${ }^{125}$ I-labelled hCG and anti$\mathrm{hCG}$ as reagents, only one peak was found with a position almost identical to that obtained with extracts from human, rat and hamster placentae (Wide \& Hobson, 1978). This was taken as support for the validity of using this radioimmunoassay method for measuring CG in the mouse in early and late pregnancy.

\section{Results}

Estimates of the CG potency of the pooled implantation sites (Day 5-12) and placentae (Day 13-19) from mice are given in Table 1 . The average content of CG per implantation site or per placenta was calculated for each day and the figures obtained (mean \pm s.e.m.) are given in Table 1. The pattern for the CG content per implantation site or per placenta from Days 5 to 19 is illustrated in Text-fig. 2.

Mouse CG could be detected in all pools of implantation sites and placentae. The control uteri from non-pregnant mice had no detectable mouse $C G$, i.e. $<6 \mathrm{U}_{\mathrm{arb}} / \mathrm{g}$ or less than 0.2 $\mathrm{U}_{\mathrm{arb}}$ /uterine horn. No CG was detectable in the blastocysts flushed on Day 5. This indicates that, provided the recovery of $C G$ in the extraction method was similar for flushed blastocysts and implantation sites, these blastocysts contain less than 1/30 of the CG content in an 
implantation site of Day 5. There was a rapid rise in the CG content from Day 5 until a maximum level was reached on Day 11. A nadir was then found on Day 14 and a second, but lower, peak on Day 16 was followed by a decline during the last 2 days of pregnancy.

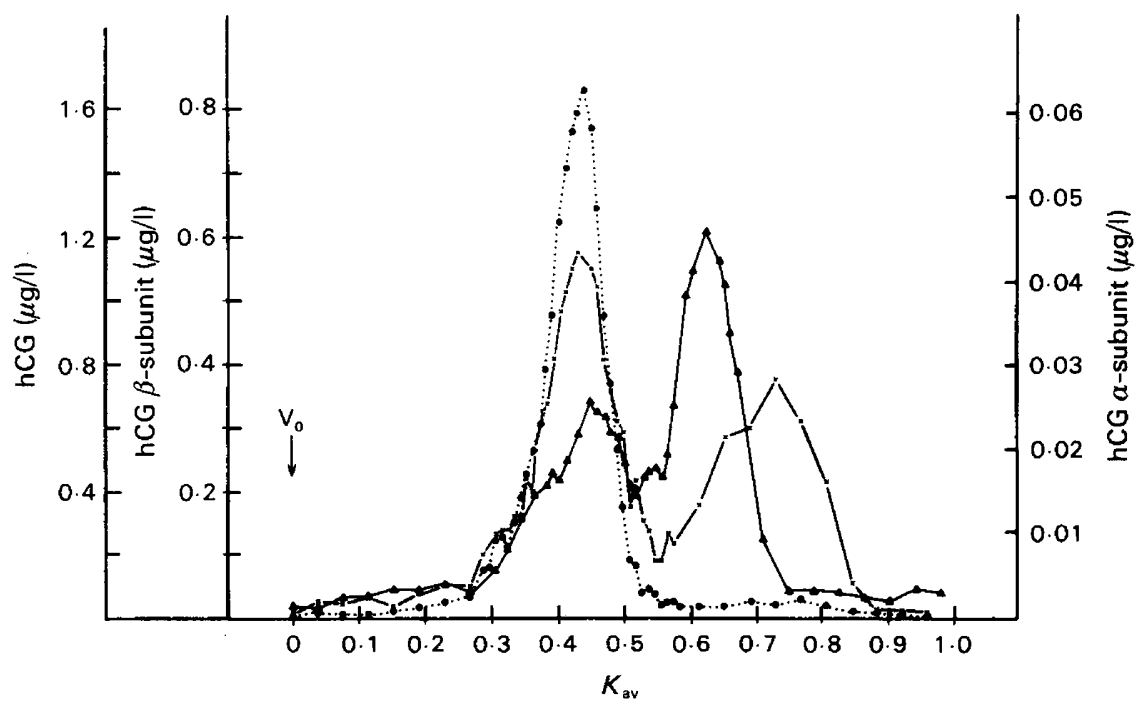

Text-fig. 1. Elution profile of an extract of a pool of 35 Day- 6 and 23 Day-7 implantation sites, chromatographed on Sephadex G-200. Each fraction was assayed in hCG (O), hCG betasubunit $(x)$, and hCG alpha-subunit $(\boldsymbol{A})$ radioimmunoassays.

Table 1. Results of radioimmunoassay for CG in extracts of pooled implantation sites (IS: Days 5-12) and placentae (Days 13-19) from mice

\begin{tabular}{|c|c|c|c|c|c|}
\hline \multirow[b]{2}{*}{$\begin{array}{l}\text { Day of } \\
\text { pregnancy }\end{array}$} & \multirow[b]{2}{*}{ No. of mice } & \multirow[b]{2}{*}{$\begin{array}{l}\text { No. of IS or } \\
\text { placentae } \\
\text { pooled }\end{array}$} & \multirow[b]{2}{*}{$\begin{array}{l}\text { Mean wet wt } \\
\text { of individual } \\
\text { IS or placentae } \\
\text { (mg) }\end{array}$} & \multicolumn{2}{|c|}{ Mouse CG } \\
\hline & & & & $\begin{array}{l}\text { Per wet wt of } \\
\text { IS or placentae } \\
\left(\mathrm{U}_{\mathrm{arb}} / \mathrm{g}\right)\end{array}$ & $\begin{array}{c}\text { Per IS or } \\
\text { placentae } \\
\left(U_{\mathrm{arb}}\right)\end{array}$ \\
\hline 5 & 5 & 59 & $4 \cdot 3$ & $75 \cdot 6 \pm 4 \cdot 1$ & $0.32 \pm 0.02$ \\
\hline 6 & 15 & 147 & 10.2 & 98.0 & 1.00 \\
\hline 7 & 5 & 52 & 17 & $91.6+4.2$ & $1.55 \pm 0.07$ \\
\hline 8 & 5 & 46 & 24 & $107.3 \pm 8.2$ & $2.55 \pm 0.19$ \\
\hline 9 & 2 & 19 & 32 & $110.6 \pm 3.5$ & $3.53 \pm 0.11$ \\
\hline 10 & 2 & 23 & 59 & $159.1+4.9$ & $9.36 \pm 0.29$ \\
\hline 11 & 3 & 28 & 105 & $137.5+6.9$ & $14.4 \pm 0.72$ \\
\hline 12 & 2 & 22 & 201 & $52.1 \pm 2.7$ & $10.5 \pm 0.54$ \\
\hline 13 & 2 & 15 & 73 & $87.0 \pm 1.9$ & $6.3 \pm 0.13$ \\
\hline 14 & 2 & 21 & 73 & $79.2 \pm 2.8$ & $5.7 \pm 0.20$ \\
\hline 15 & 1 & 12 & 110 & $72.6 \pm 1.1$ & $7.9 \pm 0.12$ \\
\hline 16 & 2 & 20 & 126 & $98.7 \pm 2.0$ & $12.4 \pm 0.28$ \\
\hline 17 & 2 & 19 & 109 & $95.6 \pm 2.3$ & $10.4 \pm 0.27$ \\
\hline 18 & 2 & 21 & 99.7 & $52.8 \pm 1.2$ & $5.26 \pm 0.12$ \\
\hline 19 & 4 & 29 & 91 & $62.0 \pm 2.6$ & $5.63 \pm 0.23$ \\
\hline
\end{tabular}

Values are mean \pm s.e.m. and are expressed in relation to the average CG content of a Day- 6 implantation site $\left(=1 U_{\mathrm{arb}}\right)$. 


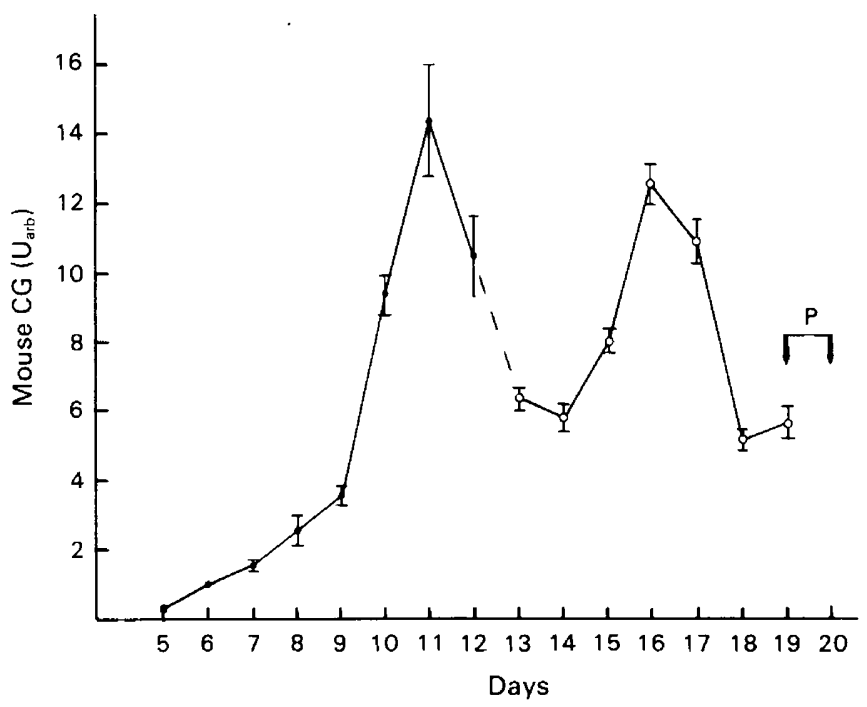

Text-fig. 2. Average content of mouse CG per implantation site (O) or per placenta (O) from early pregnancy to term in the mouse. Estimations were made with a radioimmunoassay on extracts of pooled implantation sites (Days 5-12) and of placentae (Day 13-19). The average content of a Day- 6 implantation site was designated $1 \mathrm{U}_{\text {arb. }}$. The $95 \%$ fiducial limits, as estimated from intra-assay variation, are indicated. $P=$ parturition.

\section{Discussion}

Chorionic gonadotrophin was detected in the mouse from Day 5 of pregnancy, which is the day of initiation of implantation. The possibility that the activity measured was due to the presence of pituitary LH has to be considered as it is known that human LH usually cross-reacts with hCG (Wide, Roos \& Gemzell, 1961). However, an effect of LH seems unlikely in the present case as the activity in uteri from non-pregnant mice was less than $1 / 10$ the concentration of implantation sites of Day 5 and the chromatographic studies revealed the presence of only one elution peak, similar in position to that of CG in the rat, hamster and man.

It is known that, in the mouse, ovariectomy at any time during pregnancy results in termination of gestation, while hypophysectomy can be performed only after Day 11 without disturbing pregnancy (Gardner \& Allen, 1942). This has been assumed to indicate that an ovarian stimulating factor from the conceptus is of importance during the last part of gestation in the mouse. This concept is supported by our finding of significant CG activity in all the pooled implantation sites and placentae, with a steadily increasing amount of CG from Day 5 to a maximum on Day 11. There is no previous report on the production pattern of CG throughout pregnancy in the mouse. However, in the rat, Linkie \& Niswender (1973) used a bioassay to show detectable levels of a "luteotrophic factor" in the placenta on Days 11, 12 and 13 with a maximum on Day 12. This indicates that the peak values for the placental gonadotrophin in the mouse occur at a stage of pregnancy similar to that in the rat.

Up to Day 13 of pregnancy whole implantation sites including fetuses, fetal membranes, developing placentae and surrounding uterine tissues were analysed for CG whereas from Day 13 and onwards only chorioallantoic placentae were used. The magnitude of the peak level of CG per placenta found on Day 16 was a little lower than that on Day 11 for CG per implantation site. However, we do not know to what extent CG in tissues outside the developing placentae have contributed to the levels of CG measured before Day 13 . The $95 \%$ fiducial limits shown in Text-fig. 2 were calculated from assays on pooled material and therefore do not represent the variation between individual conceptuses. If there is a large variation in CG content between conceptuses, in particular of different litters, this may have contributed significantly to the variation found between days. 
Using a radioimmunoassay for measuring pituitary $\mathrm{LH}$ in serum during pregnancy in the mouse, Murr, Bradford \& Geschwind (1974) reported detectable levels up to Day 12 of pregnancy with a maximum on Day 11 (day of vaginal plug designated Day 1 of pregnancy). No activity was detected on Days 13, 14 and 15, but raised levels were found again on Days 16-19. However, in view of the similarity between the patterns for mouse $\mathrm{LH}$ in serum during pregnancy and that of CG in implantation sites and placentae, it cannot be excluded that the activities measured in the two studies are derived from the same entity originating from the placenta. The fact that Murr et al. (1974) could not detect any cross-reacting activity in placental extracts from Days 9 to 19 may be due to the extraction procedure they used.

The presence of a gonadotrophin on the surface of mouse embryos in the 8-cell and morula stages was reported by Wiley (1974). However, he was not able to detect any gonadotrophin on the surface of uncultured mouse blastocysts. In the present study no gonadotrophic activity was detected in an extract of flushed Day-5 mouse blastocysts. In preimplantation rabbit blastocysts a gonadotrophic factor was detected by Haour \& Saxena (1974) and by Fujimoto, Euker, Riegle \& Dukelow (1975) but Sundaram, Conell \& Passantino (1975) and Holt, Heise, Wilson \& Keyes (1976) have been unable to confirm these results. The question of whether the preimplantation blastocyst synthesizes a gonadotrophin has to be studied further.

Rodents have been used successfully for study of hypothalamic-pituitary-ovarian relationships, but very little is known about the control of placental CG and the physiological role of this hormone during pregnancy. The present study has shown that $\mathrm{CG}$ can be detected and measured in the pregnant mouse from implantation to term by the use of a radioimmunoassay. These results suggest that further information on the physiological role of CG during pregnancy may be obtained from studies on mice.

We are grateful to the NIAMDD, NIH, Bethesda, U.S.A. for supplying hCG subunit preparations and antisera to these, and to AB Leo, Helsingborg, Sweden, for supplying a purified hCG preparation. We also thank $\mathrm{Mr}$ Christer Bengtsson for skilful technical assistance. Financial support was obtained from the Swedish Medical Research Council (grant 3145).

\section{References}

Fujimoto, S., Euker, J.S., Riegle, G.D. \& Dukelow, W.R. (1975) On a substance cross-reacting with luteinizing hormone in the preimplantation blastocyst fluid of the rabbit. Proc. Jap. Acad. 51, 123-125.

Gardner, W.V. \& Allen, E. (1942) Effects of hypophysectomy at mid-pregnancy in the mouse. Anat. Rec. 83, 75-97.

Haour, F. \& Saxena, B.B (1974) Detection of a gonadotrophin in rabbit blastocyst before implantation. Science, N.Y. 185, 444-445.

Hobson, B.M. (1972) Gonadotrophin concentrations in the placentae of man, the rhesus monkey and the marmoset. Folia primat. 18, 35-40.

Holt, J.A., Heise, W.F., Wilson, S.M. \& Keyes, P.L. (1976) Lack of gonadotropic activity in the rabbit blastocyst prior to implantation. Endocrinology 98, 904-909.

Linkie, D.M. \& Niswender, G.D. (1973) Characterization of rat placental luteotropin. Physiological and physiochemical properties. Biol. Reprod. 8, 48-57.

Murr, S.M., Bradford, G.E. \& Geschwind, I.I. (1974) Plasma luteinizing hormone, follicle-stimulating hormone and prolactin during pregnancy in the mouse. Endocrinology 94, 112-116.
Psychoyos, A. (1971) Method for studying changes in capillary permeability of the rat endometrium. In Methods in Mammalian Embryology, pp. 334-338. Ed. J. C. Daniel Jr. Freeman and Company, San Francisco.

Sundaram, K., Conell, K.G. \& Passantino, T. (1975) Implication of absence of hCG-like gonadotrophin in the blastocyst for control of corpus luteum function in pregnant rabbit. Nature, Lond. 256, 739741.

Wide, L. (1969) Radioimmunoassays employing immunosorbents. Acta endocr., Copenh., Suppl. 142, 207-221.

Wide L. \& Hobson, B. (1978) Chromatographic studies on a chorionic gonadotropic activity in the placenta of the rat, mouse and hamster. Uppsala J. med. Sci. 83, $1-6$.

Wide, L., Roos, P. \& Gemzell, C.A. (1961) Immunological determination of human pituitary luteinising hormone (LH). Acta endocr., Copenh. 37, 445-449.

Wiley, L.D. (1974) Presence of a gonadotrophin on the surface of preimplanted mouse embryos. Nature, Lond. 252, 715-716. 